\title{
OCCURRENCE OF GASTROINTESTINAL HELMINTHS IN CAPTIVE RHESUS MACAQUES (MACACA MULATTA)
}

\author{
Taniza Tabasshum*, Mandira Mukutmoni and Aleya Begum \\ Department of Zoology, University of Dhaka, Dhaka-1000, Bangladesh
}

\begin{abstract}
A total of 66 (sixty-six) fresh fecal samples were collected during July 2017 to October 2018 from rhesus macaques (Macaca mulatta) residing in Bangladesh National Zoo, Dhaka. Samples were analyzed applying formol-ether concentration technique. All the rhesus macaques, irrespective of age and sex, were found to be infested with one or more species of gastrointestinal (GI) helminth parasites. Ascaris spp. was noticed in all the fecal samples. Overall intensity of helminths was higher in male (38.53) that in female (31.04) comprising the maximum (58.08) in adult male $(\mathrm{p}<0.005)$. The highest intensity was of Ascaris spp. $(3.33 \pm 1.39)$ and found in adult male hosts. Young female rhesus macaques displayed the maximum intensity of Trichuris spp. (3.56 \pm 0.73$)$.
\end{abstract}

Key words: Captive, rhesus macaques, helmench, prevalence, intensity

\section{INTRODUCTION}

Non-human primates (NHP) are the closest living biological relatives, offering critical perceptions into human evolution, biology and behavior and playing important roles in the livelihoods, cultures, and religions of many societies. They contribute to tropical biodiversity and run many functions of ecological importance. Among the NHPs, rhesus macaques (Macaca mulatta) are synanthropic, thriving in human altered environments that help them to be among the most widely distributed and successful primates in the world (Hasan et al. 2013). But unsustainable human activities are now the major force driving primate species to extinction (Estrada et al. 2017).

NHPs are particularly vulnerable to parasitic infestations because many species live in unified groups characterized by frequent social exchanges which simplify parasite transmission between individuals (Stoner 1996). Studies on the prevalence of gastrointestinal (GI) parasitic infestation in NHP in several zoological gardens exhibited that $13.63 \%$ at the State Zoo, India (Bichitra et al. 2012), $19.1 \%$ at Negara Zoo in Malaysia (Lim et al. 2008), 75\% at Negede Zoo, Owerri, Nigeria (Opara et al. 2010) and 100\% at the Zoological Garden in Jos, Nigeria (Dawet et al. 2013) were infested. Wongsawad (2009) found Toxocara sp.,

*Author for correspondence: <t_tabasshum@yahoo.com>

(c) 2018 Zoological Society of Bangladesh DOI: http://dx.doi.org/10.3329/bjz.v46i2.39065 
Oesophagostomum sp., Strongyloides sp., Trichuris sp. and Capillaria sp. from Macaca assamensis in Thailand. Usually, when the parasitized animal is brought from wild to captivity, despite quarantine measures, the new condition of zoos is generally unfavorable for the animal but favorable to the parasites. The constant stress of captivity makes animals more susceptible to parasitic infection as the immune system of these captive animals becomes weak (Cordon et al. 2008). Moreover, gastrointestinal parasites of wild animals in captivity include zoonotic species affecting humans and raise public health concerns (Opara et al. 2010). Occurrence of parasites in animals kept in zoo might differ according to the type of husbandry practices and prophylactic measures. Generally, captive animals do not display alarming marks of parasitism if regular deworming practices are carried out in the zoo (Parasani et al. 2001).

The present study attempts to investigate the occurrence of endoparasitic helminths affecting rhesus macaques living in captive condition at Bangladesh National Zoo, Dhaka. We hope that information obtained from the study, will be convenient for the development of captive animal health policy.

\section{MATERIAL AND METHODS}

Study design: The present study was conducted among the 60 (male $=39$, female $=27$ ) captive rhesus macaques (Macaca mulatta) of Bangladesh National Zoo, Dhaka. The rhesus macaques were categorized into two age groups- young $(\leq 5)$ and adult $(\geq 10)$. A total of sixty-six fecal samples from sixty captive rhesus macaques were collected during monsoon; July 2017 to October 2018. We tried to exclude repeated samples. Previously sampled rhesus macaques were tagged and a few number of rhesus macaques were sampled twice (six in number).

Collection and preservation of samples: Faecal samples of rhesus macaque were collected from the cage in the early morning with the help of caretakers of the zoo. Each fecal sample was placed in a polythene bag containing $10 \%$ formalin. After collection the polythene bags mouth was knotted tightly with ribbon to avoid contamination, then it was kept in a plastic pot and each sample containing pot was sealed. The samples were marked according to age and sex. All possible aseptic measures like- hand gloves, wearing apron and shoes etc. were taken to avoid contamination.

Laboratory screening: Collected samples were analyzed by Formol-Ether Concentration Technique (Cheesbrough 1987) in the Parasitology Laboratory, Department of Zoology, University of Dhaka. Morphological identification of helminths and their different developmental stages were observed. The eggs of different helminths were observed with the help of compound (10X) microscope. 
Eggs were identified with the support of Chatterjee (1967), Soulsby (1982) and Wallach and Boever (1983).

Data analysis: Data were entered into an excel spreadsheet and transferred into SPSS version 20. Intensity and prevalence of each gastrointestinal (GI) parasite species was determined and compared statistically using regression method.

\section{RESULTS AND DISCUSSION}

In the present study, all the rhesus macaques (Macaca mulatta), irrespective of age and sex, were found to be infested with one or more species of GI helminth parasites. But intensity of infection was high in adult males (Table 1). Exploring twenty-four zoological gardens in China, Li et al. (2015) found the prevalence of gastrointestinal parasitic infection ranged from $3.77 \%$ to $100 \%$. Nath et al. (2012) recorded 13.63\% parasitic infestation in captive NHP in Assam State Zoo whereas Aviruppola et al. (2016) detected $61.1 \%$ prevalence in Dehiwala National Zoological Gardens, Sri Lanka. Various factors can explain the higher prevalence found in the present study compared to the previous studies.

Table 1. Occurrence of GI helminths in captive rhesus macaques

\begin{tabular}{llcccccc}
\hline Sex & Age & $\begin{array}{c}\text { No. } \\
\text { examined }\end{array}$ & $\begin{array}{c}\text { No. } \\
\text { positive }\end{array}$ & $\begin{array}{c}\text { Prevalence } \\
(\%)\end{array}$ & EPG & Intensity & p-value \\
\hline Male & Young & 15 & 15 & 100 & 109 & 7.27 & 0.01 \\
& Adult & 24 & 24 & 100 & 1394 & 58.08 & 0.001 \\
& Sub-total & 39 & 39 & 100 & 1503 & 38.53 & \\
Female & Young & 9 & 9 & 100 & 77 & 8.56 & 0.03 \\
& Adult & 18 & 18 & 100 & 469 & 26.06 & 0.006 \\
& Sub-total & 27 & 27 & 100 & 546 & 20.22 & \\
& Total & $\mathbf{6 6}$ & $\mathbf{6 6}$ & $\mathbf{1 0 0}$ & $\mathbf{2 0 4 9}$ & $\mathbf{3 1 . 0 4}$ & \\
\hline
\end{tabular}

In the monsoon, the climatic conditions are usually favourable for the development and maturation of parasites. All the samples were collected during monsoon, in the present study. Significantly higher prevalence of parasitic infection during monsoon season is reported by Kumar et al. (2009). The species variety and different feeding behavior may be responsible. Different species harbor different kinds of parasites and this could be the reason behind varied prevalence and intensity. The present study found the high prevalence of Ascaris spp. (100\%) and Toxocara spp. (60\%) in young male. In adult male, the maximum prevalence was of Ascaris spp. (75\%) and Hymenolepis spp. (62.05\%) $(\mathrm{p}<0.05)$ (Table 2). Generally, rhesus macaque (Macaca mulatta) lives in a social group or a community and they show various social behavior like - 
grooming, playing, foraging etc. These social behaviors create closeness among them. These interactions among hosts increase the possibility of transmission of parasites. Socially mediated exposure appears to be important for direct transmission of nematode parasites MacIntosh et al. (2012). In the present study, midst the young female the high prevalence was recorded for Ascaris spp. in both the age groups. Trichuris spp. was found to be priority infestation in young females $(\mathrm{p}<0.05)$ and Toxocara spp. in adult $(\mathrm{p}<0.05)$ (Table 3). MacIntosh et al. (2012) found that young adult females were concurrently infected by more species than were adults. Mutani et al. (2003) found that the infection rate in male rhesus macaques (88.9\%) was insignificantly dissimilar from females $(88.6 \%)$. He also found that the prevalence in adults $(88.2 \%)$ was not significantly different from the juveniles (88.9\%).

Table 2. Prevalence and intensity of GI helminths among the male young $(\mathrm{N}=15)$ and adult $(\mathbf{N}=\mathbf{2 4})$ rhesus macaques

\begin{tabular}{|c|c|c|c|c|c|}
\hline \multirow[t]{2}{*}{ Parasites } & \multirow[t]{2}{*}{ Category } & \multicolumn{2}{|c|}{ Prevalence (\%) } & \multirow[t]{2}{*}{ EPG } & \multirow{2}{*}{$\begin{array}{l}\text { Intensity } \\
( \pm \text { SD) }\end{array}$} \\
\hline & & $\mathrm{n}$ & $\%$ & & \\
\hline \multirow[t]{2}{*}{ Hymenolepis spp. } & Young & 3 & 20 & 10 & $3.33 \pm 1.39$ \\
\hline & Adult & 15 & 62.05 & 42 & $2.8 \pm 1.82$ \\
\hline \multirow[t]{2}{*}{ Taenia spp. } & Young & 6 & 40 & 6 & $1 \pm 0.51$ \\
\hline & Adult & 3 & 12.5 & 6 & $2 \pm 0.68$ \\
\hline \multirow[t]{2}{*}{ Ascaris spp. } & Young & 15 & 100 & 36 & $2.4 \pm 1.06$ \\
\hline & Adult & 18 & 75 & 43 & $2.39 \pm 1.67$ \\
\hline \multirow[t]{2}{*}{ Toxocara spp. } & Young & 9 & 60 & 18 & $2 \pm 1.21$ \\
\hline & Adult & 9 & 37.5 & 16 & $1.78 \pm 1.05$ \\
\hline \multirow[t]{2}{*}{ Trichuris spp. } & Young & 6 & 40 & 27 & $1.8 \pm 0.77$ \\
\hline & Adult & 12 & 50 & 21 & $1.75 \pm 1.08$ \\
\hline \multirow[t]{2}{*}{ Capillaria spp. } & Young & 6 & 40 & 6 & $1 \pm 0.51$ \\
\hline & Adult & 9 & 37.5 & 12 & $1.33 \pm 0.72$ \\
\hline \multirow[t]{2}{*}{ Hookworm } & Young & 6 & 40 & 6 & $1 \pm 0.51$ \\
\hline & Adult & 6 & 25 & 6 & $1 \pm 0.44$ \\
\hline
\end{tabular}

The high prevalence of Ascaris spp. may occurred due to warm temperature of the study area which is suitable for egg production. Though Taenia spp. and Toxocara spp. are generally seen in carnivores but these parasites were observed among the rhesus macaque in the present study. One of the reasons of their presence in NHP may be the strong resistance and longevity of infective eggs in the environment that ensure their transmission to another host. Furthermore, it was noticed during fecal sample collection, same mops were used for cleaning every cage's wall, which might be a reason behind the transmission of those eggs to NHP cages. 
Table 3. Prevalence and intensity of GI helminths among the female young $(N=9)$ and adult $(\mathbf{N}=18)$ rhesus macaques

\begin{tabular}{|c|c|c|c|c|c|}
\hline \multirow[t]{2}{*}{ Parasites } & \multirow[t]{2}{*}{ Category } & \multicolumn{2}{|c|}{ Prevalence (\%) } & \multirow[t]{2}{*}{ EPG } & \multirow{2}{*}{$\begin{array}{c}\text { Intensity } \\
( \pm \text { SD })\end{array}$} \\
\hline & & $\mathrm{n}$ & $\%$ & & \\
\hline \multirow[t]{2}{*}{ Hymenolepis spp. } & Young & 6 & 66.67 & 12 & $2 \pm 1.32$ \\
\hline & Adult & 9 & 50 & 27 & $3 \pm 2.20$ \\
\hline \multirow[t]{2}{*}{ Ascaris spp. } & Young & 9 & 100 & 21 & $2.33 \pm 0.50$ \\
\hline & Adult & 18 & 100 & 30 & $1.67 \pm 0.77$ \\
\hline \multirow[t]{2}{*}{ Toxocara spp. } & Young & 3 & 33.33 & 3 & $1 \pm 0.50$ \\
\hline & Adult & 18 & 100 & 30 & $1.67 \pm 0.77$ \\
\hline \multirow[t]{2}{*}{ Trichuris spp. } & Young & 9 & 100 & 32 & $3.56 \pm 0.73$ \\
\hline & Adult & 6 & 33.33 & 6 & $1 \pm 0.49$ \\
\hline \multirow[t]{2}{*}{ Capillaria spp. } & Young & 6 & 66.67 & 9 & $1.5 \pm 0.87$ \\
\hline & Adult & 9 & 50 & 13 & $1.44 \pm 0.83$ \\
\hline \multirow[t]{2}{*}{ Hookworm } & Young & & - & - & - \\
\hline & Adult & 3 & 16.67 & 3 & $1 \pm 0.38$ \\
\hline
\end{tabular}

Species specific intensity of infection was quite inconsequential in the present study. In young male, Hymenolepis spp. (3.33 \pm 1.39 in young; $2.8 \pm 1.82$ in adult) showed the highest intensity followed by Ascaris spp. $(2.4 \pm 1.06$ in young; $2.39 \pm 1.67$ in adult) (Table 2). MacIntosh et al. (2010) found a male bias in egg per gram (EPG) and prevalence of infection with directly transmitted species in Japanese macaques, except in the prevalence of Oesophagostomum aculeatum and no sex bias in the other parasites. Infection with $O$. aculeatum showed a female bias in prevalence among young adults. Variation in hosts immune response because of malnutrition and stress may be accountable for parasite intensity. Parasite-host interaction may be influenced by various geographical habitat, distribution and environmental condition. Favourable environment aids in spreading parasites quickly. In the present study, among the young female, Trichuris spp. showed the highest intensity (3.56 \pm 0.73 ) followed by Hymenolepis spp. (3.33 \pm 1.39$)$. No hookworm infection was encountered among the young females though the thin skin of young provides better entry of hookworm (Table 3).

\section{CONCLUSION}

High levels of parasitism in captive animals can be attributed to crossspecies transmission and stress due to imprisonment which aggravate parasitic infections to the point of demise. Although anthelmintic drugs are used in Dhaka zoo twice in a year but may be the doses are not enough to acquire defense against gastrointestinal parasites. As a result, the perimeter of parasite infestation is high. In zoos there are an increasing risk of parasite transmission from rhesus macaques to visitors or keepers as a result of direct or indirect 
contact through contaminated food, water and hands. Effective control actions should be run by the zoo authorities to lessen the probability of environmental contamination.

\section{LITERATURE CITED}

AVIRUPPOLA, A.J.M.K., RAJAPAKSE, R.P.V.J. and RAJAKARUNA, R.S. 2016. Coprological survey of gastrointestinal parasites of mammals in Dehiwala National Zoological Gardens, Sri Lanka. Ceylon J. Sci. 45(1): 83-96.

BICHITRA, G. N., SAIDUL, I. and APURBA, C. 2012. Prevalence of parasitic infection in captive nonhuman primates of Assam State Zoo, India. Vet. World. 5(10): 614-616.

CHATTERJEE, K. D. 1967. Parasitology: (protozoology and helminthology) in relation to clinical medicine. Sree Saraswaty Press, India. 208-214 pp.

CHEESBROUGH, M. 1987. Medical Laboratory Manual for Tropical Countries. ELBS Publishing, UK. 413-527 pp.

CORDON, G.P., PRADOS, A.H., ROMERO, D., MORENO, S.M., PONTES, A., OSUNA, A. and ROSALES, M.J. 2008. Intestinal parasitism in the animals of the zoological garden Pena Escrita. Vet. Parasitol. 156: 302-309.

DAWET, A., YAKUBU, D.P. and BUTU, H.M. 2013. Survey of gastrointestinal parasites of nonhuman primates in Jos zoological garden. J. Primatol. 2(1): 1-3.

ESTRADA, A., GARBER, P.A., RYlANDS, A.B., ROOS, C. and FERNANDEZ-DUQUE, E. 2017. Impending extinction crisis of the world's primates: Why primates matter. Sci. Adv. 3: e1600946.

HASAN, M.K., FEEROZ, M.M., JONES-ENGEL, L., ENGEL, G.A. and SMITH, D.G. 2014. Diversity and molecular phylogeny of Rhesus macaques (Macaca mulatta) of Bangladesh. Am. J. Primatol. 76: 1074-1104.

KUMAR, S., QUASIM, A., KAUSHIK, P. and SAMANTARAY, S. 2009. Prevalence of parasitic infections in zoo animals of Sanjay Gandhi Biological Park, Patna. J. Vet. Pub. Hlth. 7(2): 137-139

LI, M., ZHAO, B., LI, B., WANG, Q., NIU, L., DENG, J., GU, X., PENG, X., WANG, T. and YANG, G. 2015. Prevalence of gastrointestinal parasites in captive non-human primates of twenty-four zoological gardens in China. J. Med. Primatol. 44: 168-173.

LIM, Y.A.L., NGUI, R., SHUKURI, J., ROHELA, M. and MAT-NAI, H.R. 2008. Intestinal parasites in various animals at a zoo in Malaysia. Vet. Parasitol. 157: 154-159.

MACINTOSH, A.J.J., HERNANDEZ, A.D. and HUFFMAN, M.A. 2010. Host age, sex and reproductive seasonality affect nematode parasitism in wild Japanese macaques. Primates 51: 353-364.

MACINTOSH, A.J.J., JACOBS, A., GARCIA, C., SHIMIZU, K., MOURI, K. and HUFFMAN M. A. 2012. Monkeys in the middle: Parasite transmission through the social network of a wild primate. PLOS. ONE. 7(12): e51144.

MUTANI, A., RHYND, K. and BROWN, G. 2003. A Preliminary Investigation on the gastrointestinal helminths of the Barbados Green Monkey, Cercopithecus aethiops sabaeus. Rev. Inst. Med. Trop. Sao. Paulo. 45(4): 193-195.

NATH, B. G., ISLAM, S. and CHAKRABORTY, A. 2012. Prevalence of parasitic infection in captive non-human primates of Assam State Zoo, India. Vet. World. 5(10): 614-616. 
OPARA, M. N., OSUJI, C. T. and OPARA, J. A. 2010. Gastrointestinal parasitism in captive animals at the zoological garden, Negede, Owerri, Southeast Nigeria. Rep. Opin. 2(5): 21-28.

PARASANI, H.R., MOMIN, R.R., MARADIN, M.G. and VEER, S. 2001. A survey of gastrointestinal parasites of captive animals at Rajkot munipical corporation zoo, Rajkot, Gujarat. Zoos. Print. J. 16(10): 604-606.

SOULSBY, E.J.L. 1982. Helminths, Arthopods and Protozoa of Domesticated Animals. Bailliere and Tindal, London. 766-771pp.

STONER, K.E. 1996. Prevalence and intensity of intestinal parasites in mantled howling monkeys (Alouatta palliata) in Northeastern Costa Rica: Implications for conservation biology. Conserv. Biol. 10(2): 539-546.

WALLACH, J.D. and BOEVER, W.J. 1983. Diseases of exotic animals: medical and surgical management. Saunders, Philadelphia. 212-1159 pp.

WONGSAWAD, C. 2009. Coprodiagnosis using smear and sedimentation techniques to detect intestinal parasites of Assamese Macaques, Macaca assamensis from Wat Tham-Pla, Chiang Rai Province. Trench Res. Sci. Technol. 1(1): 65-70.

(Manuscript received on 12 September, 2018; revised on 26 November, 2018) 